\title{
APPENDIX
}

\section{Danger Assessment: Women With Male or Female Partners}




\section{DANGER ASSESSMENT}

Jacquelyn C. Campbell, PhD, RN

Copyright (C) 1985, 1988, 2001

Several risk factors have been associated with homicides (murders) of both batterers and battered women in research conducted after the murders have taken place. We cannot predict what will happen in your case, but we would like you to be aware of the danger of homicide in situations of severe battering and for you to see how many of the risk factors apply to your situation.

Using the calendar, please mark the approximate dates during the past year when you were beaten by your husband or partner. Write on that date how bad the incident was according to the following scale:

1. Slapping, pushing; no injuries and/or lasting pain

2. Punching, kicking; bruises, cuts, and/or lasting pain

3. "Beating up"; severe contusions, burns, broken bones

4. Threat to use weapon; head injury, internal injury, permanent injury

5. Use of weapon; wounds from weapon

(If any of the descriptions for the higher number apply, use the higher number.)

Mark Yes or No for each of the following. ("He" refers to your husband, partner, ex-husband, ex-partner, or whoever is current physically hurting you.)

1. Has the physical violence increased in severity or frequency over the past year?

2. Has he ever used a weapon against you or threatened you with a weapon?

3. Does he ever try to choke you?

4. Does he own a gun?

5. Has he ever forced you to have sex when you did not wish to do so?

6. Does he use drugs? By drugs, I mean "uppers" or amphetamines, speed, angel dust, cocaine, "crack," street drugs, or mixtures.

7. Does he threaten to kill you and/or do you believe he is capable of killing you?

8. Is he drunk every day or almost every day? (In terms of quantity of alcohol)

9. Does he control most or all of your daily activities? For instance, does he tell you who you can be friends with, when you can see your family, how much money you can use, or when you can take the car? (If he tries, but you do not let him, check here:

10. Have you ever been beaten by him while you were pregnant? (If you have never been pregnant by him, check here: 
11. Is he violently and constantly jealous of you? (For instance, does he say "If I can't have you, no one can.")

12. Have you ever threatened or tried to commit suicide?

13. Has he ever threatened or tried to commit suicide?

14. Does he threaten to harm your children?

15. Do you have a child that is not his?

16. Is he unemployed?

17. Have you left him during the past year? (If you never lived with him, check here:

18. Do you currently have another (different) intimate partner?

19. Does he follow or spy on you, leave threatening notes, destroy your property, or call you when you do not want him to?

Total "Yes" Answers

Thank you. Please talk to your nurse, advocate, or counselor about what the Danger Assessment means in terms of your situation.

Source: Used with permission.

Campbell, J. C., Webster, D. W., \& Glass, N. (2009). The danger assessment: Validation of a lethality risk assessment instrument for intimate partner femicide. Journal of Interpersonal Violence, 24(4), 653-674.

\section{Resources}

www.dangerassessment.org www.dangerassessment.org/DA.aspx www.dangerassessment.org/uploads/permissionword.pdf 


\begin{tabular}{|l} 
DANGER ASSESSMENT-Revised \\
For Use in Abusive Female Same-Sex Relationships \\
Nancy Glass, PhD, MPH, RN and Jacquelyn C. Campbell, PhD, RN, FAAN \\
Copyright 2007 Johns Hopkins University, School of Nursing
\end{tabular}




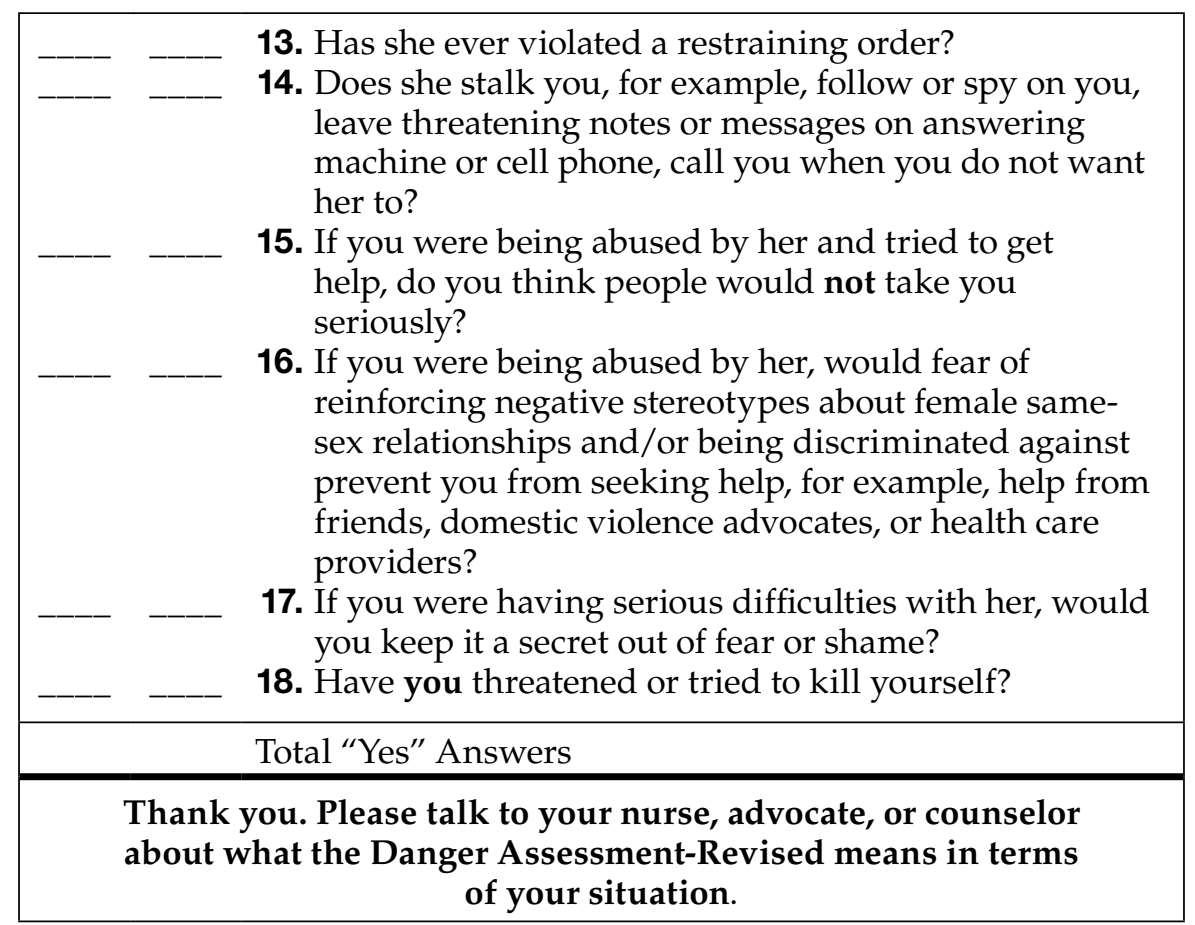

\section{Weighted Score for DA-R}

Yes to Item 1 = 4 points; Yes to Item 2 = 3 points; Yes to Item $3=2$ points; Yes to Item $4=2$ points; Yes to Item $5=2$ points; Yes to Item $6=2$ points; Yes to Items $7-17=1$ point each

Item 18 is not scored, assessing her suicide attempt

Source: Used with permission.

Glass, N., Perrin, N., Hanson, G., Bloom, T., Gardner, E., \& Campbell, J. C. (2008). Risk for reassault in abusive female same-sex relationships. American Journal of Public Health, 98(6), 1021-1027. 